\title{
POBREZA E IDENTIDADE: A CONSTRUÇÃO DO AUTOCONCEITO DE INDIVÍDUOS PERIFÉRICOS
}

\section{POVERTY AND IDENTITY: THE CONSTRUCTION OF SELF-CONCEPT OF PERIPHERAL INDIVIDUALS}

\author{
Henrique da Silva dos Santos \\ Acadêmico de Psicologia, Centro Universitário UNIFAFIBE, Brasil. \\ E-mail: henrique.psico2017@gmail.com
}

Recebido: 05/04/2021 - Aceito: 05/04/2021

\section{Resumo}

O Brasil desde sua origem enfrenta a desigualdade social, que causa muita pobreza e miséria em boa parte de nossa população. O objetivo do trabalho foi compreender como a pobreza e a miséria pode influenciar na construção do autoconceito de um indivíduo, para isso foi realizada uma revisão bibliográfica de trabalhos que abordavam temas relacionados às palavras-chave. Foi possível concluir que a sociedade brasileira está inserida em um ciclo, na qual as instituições estão dispostas a manter a relação de opressão sobre as classes mais populares, e isso prejudica na construção da identidade de jovens periféricos.

Palavras-chave: Autoconceito; identidade; periferia; pobreza.

\begin{abstract}
Brazil from its origin faces social inequality, which causes much poverty and misery in much of our population. The objective of the work was to understand how poverty and misery can influence the construction of an individual's self-concept, a bibliographical review of work that addressed issues related to keywords was carried out. It was possible to conclude that the Brazilian society is inserted in a cycle, in which the institutions are willing to maintain the list of oppression on the most popular classes, and this is prejudiced in the construction of the identity of young peripherals.
\end{abstract}

Keywords: Self-concept; identity; periphery; poverty.

\section{Introdução}

O Brasil apresenta um enorme déficit social, com uma grande desigualdade entre a população. De forma ampla, a desigualdade deve ser observada sob o 
tratamento dado por uma sociedade aos diversos grupos que dela fazem parte, e avaliada pela distribuição de recursos, reconhecimentos oportunidades ou bemestar entre os seus membros (BEATO \& REIS, 2000; COSTA \& SILVA, 2020).

Há o estabelecimento das chamadas "linhas de pobreza", para nortear pesquisas sobre a pobreza no país, tais linhas têm como objetivo traçar um limite imaginário da população, a dividindo entre pobre e não-pobres, a partir do critério de insuficiência de renda estabelecido por hábitos de consumo e necessidades calóricas mínimas (DANTAS; OLIVEIRA \& YAMAMOTO, 2010). Além disso, a sociedade como um todo construiu uma imagem negativa sobre a periferia, com 0 principal objetivo de manter a estrutura simbólica de poder das relações de poder socioeconômicas e conta com a ajuda da mídia, como um espaço de (re)produção dos estereótipos, imputa à periferia características exclusivas de violência e, aos jovens, o papel de seus principais perpetradores (FERREIRA et al, 2020).

Sob a óptica da Psicologia Social, o todo social influência direta e indiretamente o individuo, pois as palavras, ações ou simplesmente a presença de outras pessoas surtem efeito sobre nossos pensamentos, atitudes ou comportamentos (ARONSON; WILSON \& AKERT, 2018).

Deste modo, o objetivo do presente estudo é realizar uma pesquisa descritiva e qualitativa, através de uma revisão bibliográfica acerca do influencia da pobreza sobre a construção do autoconceito de indivíduos periféricos. Além disso, visa como resultado contribuir para estudos futuros e abranger o debate acerca do tema.

\section{Revisão Bibliográfica}

\section{DESIGUALDADE SOCIAL NO BRASIL}

O Brasil, assim como o restante da América Latina, enfrenta peculiaridade por conta de sua colonização, tais como a desigualdade social e econômica (MENDONÇA, 2013), estas não encontradas em outra parte do mundo. Alguns estudos apresentam que a desigualdade brasileira teve influencia dos europeus, da escravidão e dos grandes latifúndios, e esses aspectos são considerados hoje como os pilares da má distribuição de renda. Com o início da era moderna, 
juntamente ao grande crescimento econômico do país, houve um aumento da concentração de renda por parte de uma pequena parcela da população, enquanto para o restante sobrou o desemprego, a miséria, a fome, a mortalidade infantil, a pouca escolaridade, a violência e a desnutrição (NUNES, 2019).

Até os anos de 1930, a desigualdade social não esteve no foco do Estado, e era tratada com indiferença. Apenas no governo de Getúlio Vargas que a desigualdade social ganhou a atenção (OLIVEIRA, 2015), pois o então presidente criou políticas públicas direcionadas para a classe trabalhadora, e mesmo buscando manter as relações hierárquicas, se preocupava em diminuir a desigualdade social do país (NETO, 2013).

Mas essa preocupação durou pouco, porque a partir de 1964 no período militar, o Estado se afunda em um processo de privatização dos serviços públicos, e tanto a saúde quanto a educação se tornaram mercadoria, ficando inacessíveis para grande parte da população, o que acentuou ainda mais a diferença entre as classes sociais (JARDIM; ARON, 2016).

Com o fim do período militar o Brasil busca um caminho para a redemocratização, e para isso é promulgada a Constituição Federal de 1988, que em seus princípios básicos visa garantir a igualdade e a dignidade da pessoa humana e apresenta como objetivo fundamental, no art. $3^{\circ}$, $\S 3^{\circ}$, erradicar a pobreza e a marginalização e reduzir as desigualdades sociais e regionais (SILVA, 2013).

A Constituição Federal de 1988 instituiu na Brasil o Estado Democrático de Direito, assegurando assim um rol de direitos que inscrevem a população como cidadãos e cidadãs, postulando como objetivo do Estado à erradicação da pobreza e redução as desigualdades sociais e regionais (BRASIL, 1988). A queda da desigualdade, através das transferências governamentais e compreensão salarial, ou pelo acesso a serviços, como saúde e educação, ocorreu de fato a partir da década de 1990, e a maior redução da desigualdade de renda ocorreu no governo do Partido dos Trabalhadores - PT (ARRETCHE, 2018). 
Porém, um pouco antes do início da pandemia de COVID-19 o Brasil apresentava um retorno no crescimento da desigualdade social, com um aumento no número de desempregados e de trabalhadores informais, já com o inicio da pandemia esse número aumentou ainda mais, com 13,9 milhões de desempregados no quarto trimestre de 2020 (IBGE, 2021). Além disso, a pandemia acendeu os holofotes para a diferença da pandemia a depender da classe social, apresentando uma "pandemia de rico e a pandemia de pobre", na qual aqueles com maior poder aquisitivo atravessam a pandemia sem muitos sacrifícios, por outro lado, as classes mais populares não conseguem cumprir a recomendação de isolamento e distanciamento social, pois precisam buscar novas formas de renda, uma vez que para os mais pobres, ficar em casa é sinônimo de morrer de fome (BARDI et al, 2020).

Deve-se ressaltar, que por de trás da desigualdade social que assola o país desde a sua origem, há uma "força", que impede qualquer oportunidade de desenvolvimento. A América Latina desde a sua origem é globalizada, em que desde a sua colonização, suas riquezas naturais despertam a cobiça dos países hegemônicos. Para garantir que a América Latina continue sobre seu poder e "subdesenvolvidos", os países hegemônicos utilizam dos políticos como suas "marionetes particulares", na construção de políticas que contribuem para a desigualdade (MENDONÇA, 2013).

\section{O AUTOCONCEITO}

Durante nosso desenvolvimento, é comum se perguntar: "Quem sou eu?", e essa pergunta abrange muitos aspectos, como nosso físico, nossa personalidade, hábitos, pertença a um grupo social etc. Tal processo faz parte de um processo chamado autoconceito, que se refere a ideias que temos sobre o nosso eu. Essas ideias partem de crenças, que podem ser corretas ou não, que construímos ao longo de nossa vida sobre quem somos, e essas crenças estão, especialmente, relacionadas as nossas interações sociais (RODRIGUES; ASSMAR \& JABLONSKI, 2015). 
Revista Multidisciplinar do Nordeste Mineiro, v.1,

2021/01

ISSN 2178-6925

O autoconceito pode ser considerado como o conjunto de pensamentos e sentimentos que se referem ao self enquanto objeto, sendo formado a partir de experiências e das interpretações que o indivíduo realiza acerca do ambiente que está inserido (ANDRADE, 2016).

Pode-se dizer que há quatro tipos de influências que contribuem para a construção do autoconceito: a primeira é o modo que as pessoas observam o indivíduo, aqui o indivíduo desenvolve o fenômeno de espelho e passa a observar a maneira que outras pessoas a consideram, este processo ocorre através do feedback que o indivíduo recebe; a segunda é o desempenho do indivíduo em situações especificas, com isso pode julgar se saiu bem ou mal, ou se é competente ou incompetente; a terceira é o confronto da conduta com seus pares sociais e; a quarta é a avaliação de um comportamento específico em função de valores veiculados por grupos normativos (SERRA, 1988).

O autoconceito está diretamente relacionado à autoestima. Se o autoconceito faz as diversas faces da imagem de um individuo, a autoestima está relacionada com a autoavaliação, ou seja, como o indivíduo se coloca frente ao mundo e os sentimentos como se vê (SCHULTHEISZ \& APRILE, 2013).

\section{CONSTRUÇÃO DO AUTOCONCEITO EM INDIVÍDUO DAS CLASSES POPULARES}

Um dos aspectos que influenciam na construção do autoconceito de um indivíduo é a forma como outras pessoas o observam. Para compreendermos melhor como as pessoas mais pobres são vistas pelo restante da sociedade, podemos mencionar o conceito de periferia, que é o local onde está a maior parte da população que sofre com vulnerabilidade social, pobreza e extrema pobreza. Resumidamente, periferia diz respeito ao que é secundário, irrelevante, e até anormal quando comparado ao central, importante e desenvolvido. Para alguns teóricos, a periferia é o obstáculo no caminho ao desenvolvimento, de países "subdesenvolvidos" (SOUZA, 1997). Deste modo, podemos compreender que as classes mais populares são culpabilizadas pelo atraso no desenvolvimento do país, logo, se tornam o opróbrio de uma sociedade "subdesenvolvida". 
Com isso, a periferia recebe um papel social, que consiste em expectativas sobre comportamento ou modos de portar de um indivíduo inserido em determinado grupo social (SAVOIA \& CORNICK, 1989), tal papel é o de serem submissos e aceitarem sua situação. Este papel de submissão é uma herança da colonização, que criou a identidade de oprimido e de explorado, que pode gerar diversos posicionamentos, como: servilismo, fatalismo e de violência (MOURA; XIMENES \& SARRIERA, 2014).

Em nossa sociedade a pobreza está revestida por um status social de desvalorizada e estigmatizada, com isso, os pobres são obrigados a viverem em situação de isolamento. As classes populares sofrem também com a humilhação social, que é o efeito psicossocial mais evidente em uma sociedade de classes. Esta humilhação é uma repetição ancestral de violência material e psicológica, que ultrapassa gerações, e é nefasta por moldar a subjetividade do indivíduo, prejudicando sua capacidade de criar, ferindo sua percepção sobre si e também sua autoestima. Além disso, o Brasil está inserido em uma realidade opressora e de marginalização, que coloca o oprimido em uma posição de culpa para sua situação, e de incapacidade de promover qualquer mudança. Está submissão e conformismo da realidade é reproduzido pelas ideologias, relacionamentos, instituições e atitudes que estão a serviço da permanência da realidade de opressão (CIDADE; MOURA \& XIMENES, 2012; FERREIRA \& LATORRE, 2012; PAUGAM, 2014).

O sentimento de culpa pode ser explicado pela ideia de meritocracia, construída pela elite econômica e pela classe média, para camuflar seus privilégios. $\mathrm{Na}$ ideologia da meritocracia, as pessoas devem ser recompensadas de forma proporcional aos seus "esforços", porém ao promover o mérito individual, oculta a existência de configurações da estrutura social, na qual distribuem desigualdade nas oportunidades de desenvolver competências necessárias (WACHELKE, 2020).

Não é difícil compreender qual a relação entre culpa e meritocracia, se observarmos que a classe média, desde a infância de seus filhos investe em uma boa educação, cultura, atividades extracurriculares e leitura desde cedo, irão pegar 
gosto pelo estudo, tornando mais fácil ingressarem futuramente em uma boa universidade e também em um trabalho com grande prestigio e boa remuneração. Por outro lado, as classes mais populares tem acesso apenas à educação precária, raramente a cultura, e em muitos casos precisam abandonar a escola para ajudar no sustento da família, e quando não conseguem cursar o ensino superior ou um bom emprego, sente que não "lutou" o suficiente para ter "sucesso", e se culpa por isso (JESSÉ, 2019; SILVA; SILVA \& RAMOS, 2020).

Se pensarmos em um jovem, que está construindo seu autoconceito e se depara com uma sociedade que o usa como bode expiatório, em que é estigmatizado como violento, perigoso e até mesmo inferior, sofre um impedimento de transformação em sua identidade, impossibilitando mudanças no reconhecimento de sua identidade em relação à sociedade (MOURA \& XIMENES, 2016).

O sentimento de inferioridade das classes mais populares está relacionado também ao ambiente em que vivem, com lixo nas ruas, sem asfalto, sem saneamento, sem serviços de qualidade e violência. Este ambiente faz com que as pessoas afetadas diretamente pela desigualdade social, percam a confiança no Estado, pois compreendem que foram esquecidas (RODRIGUES, 2019).

O Estado junto com a mídia auxilia na rotulação da periferia, e este rótulo induz que o indivíduo rotulado se porte da maneira que esperamos, mesmo que de forma inconsciente (RODRIGUES; ASSMAR \& JABLONSKI, 2015). A mídia contribui neste processo ao apresentarem de maneira sensacionalista e tendenciosa a violência do oprimido, e não a violência real, ou seja, aquela realizada pelo Estado. Por ser tendenciosa, a mídia descarta qualquer análise social do problema, e instiga a população a punir severamente, os jovens de periferia (LAMARÃO NETO \& TEXEIRA, 2021) que passam a serem vistos como violentos e perigosos.

O estigma interfere de forma negativa na construção da identidade e autoestima dos jovens. Ao serem estigmatizados, os jovens internalizam tal estigma e isso pode comprometer sua formação profissional, pois ao não 
Revista Multidisciplinar do Nordeste Mineiro, v.1,

2021/01

ISSN 2178-6925

conseguirem reconhecer sua identidade, esses indivíduos, consequentemente, irá diminuir sua autoestima, desacreditar e reprimir suas potencialidades (FERREIA et al, 2020).

\section{Considerações Finais}

A partir da revisão bibliográfica, foi possível observar que há uma estrutura social que está disposta a manter as posições de opressão, não oferecendo oportunidades para que os indivíduos inseridos nas periferias consigam melhorar sua situação. Além disso, o Estado em parceria com a mídia contribui na estigmatização da população mais pobre, e esta estigmatização esconde os privilégios da elite econômica e da classe média, e culpa as classes populares por permanecerem em situação precária, quando na verdade, os pobres enfrentam inúmeros obstáculos.

O estigma construído sobre a periferia influencia diretamente na construção da identidade dos jovens inseridos nestas comunidades, que introjetam a ideia de que são inferiores ao restante da sociedade, e por isso não há nada que possam fazer, a não ser permanecer na situação que está.

\section{Referências}

ANDRADE, C. A construção da identidade, auto-conceito e autonomia em adultos emergentes. Psicologia Escolar e Educacional. v. 20, n. 1, 2016

ARONSON, E.; WILSON, T. \& AKERT, R. Psicologia Social. 8ª ed. Rio de Janeiro: LTC. 2018.

ARRETCHE, M. Democracia e redução da desigualdade econômica no Brasil: Inclusão dos outsiders. Revista Brasileira de Ciências Sociais. v. 33, n. 96, 2018.

BARDI, G. Pandemia, desigualdade social e necropolítica no Brasil: Reflexões a partir da terapia ocupacional social. Revisbrato. v. 4, n. 2, 2020.

BEATO, C. \& REIS, I. A. Desigualdade, desenvolvimento socioeconômico e crime. Desigualdade e pobreza no Brasil. 2020.

BRASIL. Constituição Federal da República Federativa do Brasil. Brasília, DF; Senado, 1988.

CIDADE, E.; MOURA J. \& XIMENES, V. Implicações psicológicas da pobreza na 
Revista Multidisciplinar do Nordeste Mineiro, v.1, 2021/01

ISSN 2178-6925

vida do povo latino-americano. Psicologia Argumentos. v. 30, n. 68, 2012. COSTA, B. \& SILVA, M. (Org.). Desigualdade para inconformados: dimensões e enfrentamentos das desigualdades no Brasil. Porto Alegre: UFRGS. 2020.

DANTAS, C. M.; OLIVEIRA, I. \& YAMAMOTO, O. H. Psicologia e pobreza no Brasil: produção de conhecimento e atuação profissional. Psicologia \& Sociedade. v. 22, n. 1, 2010.

FERREIRA, M. A.; LATORRE, M. R. Desigualdade social e os estudos epidemiológicos: uma reflexão. Ciência \& Saúde Coletiva. v. 17, n. 9, 2012.

FERREIRA, S. M. et al. Periferia, violência e estigma sob o enfoque da promoção da saúde: relato de experiência. Pesquisas e Práticas Psicossociais. v. 16, n. 1, 2020.

INSTITUTO BRASILEIRO DE GEOGRAFIA E ESTATÍSTICA. Desemprego em 2020. Rio de Janeiro: IBGE, 2021.

JARDIM, L. E. \& ARON, M. L. Ditadura brasileira e seus desdobramentos em Desigualdade e Humilhação Social. Revista Angelus Novus. v. 7, n. 12, 2016.

LAMARÃO NETO, H. \& TEXEIRA, E. M. Violência (estrutural) e criminalidade patrimonial. Brasilian Journal of Development. v. 7, n. 3, 2021.

MENDONÇA, J. L. A América Latina: da desigualdade social à desigualdade econômica ou características e variações de um mesmo tema. In GARCIA, M. L. \&RAIZER, E. C. A questão social e as políticas sociais no contexto latinoamericano. Vitória: EDUFES. p. 112-128, 2013.

MOURA, J. \& XIMENES, V. A identidade social estigmatizada de pobre: uma construção opressora. Fractal: Revista de Psicologia. v. 28, n. 1, 2016.

MOURA, J.; XIMENES, V. \& SARRIERA, J. A construção opressora da pobreza no Brasil e suas consequências no psiquismo. Quaderns de Psicologia. v. 16, n. 2, 2014.

NUNES, T. Desigualdade de renda no Brasil: consequências ou entraves ao crescimento econômico? Revista Interfaces do Conhecimento. v. 1, n. 2. 2019.

OLIVEIRA, F. Desigualdade social: uma trajetória de insistência no Brasil. In VII Jornada Internacional de Políticas Públicas. São Luís, MA, 2015.

PAUGAM, S. O enfraquecimento e a ruptura dos vínculos sociais: uma dimensão essencial do processo de desqualificação social. In. SAWAIA, B. (Org.). As artimanhas da exclusão: análise psicossocial e ética da desigualdade social. 14르 ed. Petrópolis: Vozes. p. 69-88, 2014.

RODRIGUES, A.; ASSMAR, E. \& JABLONSKI, B. Psicologia Social. 32ª ed. Petrópolis: Vozes. 2015.

RODRIGUES, P. Desigualdade e violência no século XX. In. REIS, T.; OLIVEIRA, M. \& SOUZA, C. Desigualdade, violência, e relações de poder na História. Boa Vista: Editora da UFRR, 2019. 
Revista Multidisciplinar do Nordeste Mineiro, v.1,

SAVOIA, M. G.\& CORNICK M. A. Psicologia social. 2ª ed. São Paulo: Mcgrawill, 1989.

SCHULTHEISZ, T. \& APRILE, M. R. Autoestima, conceitos correlatos e avaliação. Revista Equilíbrio Corporal e Saúde. v. 5, n. 1, 2013.

SERRA, A.. O auto-conceito. Análise Psicológica. v. 2, n. 6, 1988.

SILVA, M. V; SILVA, G. \& RAMO, J. B. Trabalho infantil no Brasil e na Amazônia legal: uma breve análise. Rosearch, Society and Development. v. 9, n.12, 2021

SILVA, W. A Constituição de 1988 e a nova ordem social: A efetivação dos princípios da igualdade e da dignidade da pessoa humana. Revista de Informação Legislativa. v. 50, n. 200, 2013.

SOUZA, C. Sociologia: Introdução à ciência da sociedade. $2^{a}$ ed. São Paulo: Moderna, 1997.

WACHELKE, J. et al. Causas da pobreza, meritocracia e igualdade: um estudo de crenças de adolescentes como mediação social. Mediaciones Sociales. v. 19, 2020. 
Revista Multidisciplinar do Nordeste Mineiro, v.1, 2021/01

ISSN 2178-6925

Relatório do Software Anti-plágio CopySpider

Para mais detalhes sobre o CopySpider, acesse: https://copyspider.com.br

\section{Instruções}

Este relatório apresenta na próxima página uma tabela na qual cada linha associa o conteúdo do arquivo de entrada com um documento encontrado na internet (para "Busca em arquivos da internet") ou do arquivo de entrada com outro arquivo em seu computador (para "Pesquisa em arquivos locais"). A quantidade de termos comuns representa um fator utilizado no cálculo de Similaridade dos arquivos sendo comparados. Quanto maior a quantidade de termos comuns, maior a similaridade entre os arquivos. É importante destacar que o limite de $3 \%$ representa uma estatística de semelhança e não um "índice de plágio". Por exemplo, documentos que citam de forma direta (transcrição) outros documentos, podem ter uma similaridade maior do que $3 \%$ e ainda assim não podem ser caracterizados como plágio. Há sempre a necessidade do avaliador fazer uma análise para decidir se as semelhanças encontradas caracterizam ou não o problema de plágio ou mesmo de erro de formatação ou adequação às normas de referências bibliográficas. Para cada par de arquivos, apresenta-se uma comparação dos termos semelhantes, os quais aparecem em vermelho.

Veja também:

Analisando o resultado do CopySpider

Qual o percentual aceitável para ser considerado plágio? 